\title{
Instrução-focada-na-forma, lingualização e aprendizagem de ILE por aprendizes brasileiros
}

\section{Form-focused instruction, languaging and the learning of English as a foreign language (EFL) by Brazilian learners}

Rejane Teixeira Vidal*

UFF

RESUMO: Este estudo examina o conceito de lingualização (SWAIN, 2006) em contexto de instrução-focada-na-forma e o seu papel como uma importante ferramenta a ser utilizada por aprendizes de brasileiros de língua estrangeira, sejam avançados ou de nível elementar, se o objetivo é a precisão linguística. Com o apoio da teoria sociocultural da mente de Vygotsky (1978) e com base nos estudo desenvolvidos por Swain no contexto canadense, assim como nos de Vidal (2003) em contexto brasileiro, ambos com alunos avançados, a investigação mostra como aprendizes brasileiros de língua inglesa de diferentes níveis de proficiência e de diferentes realidades instrucionais se beneficiam com a lingualização - o processo de se construir significado e moldar conhecimento e experiência por meio da própria língua-alvo. Análise qualitativa de diálogo colaborativo e de feedback corretivo fornecem evidências para a reivindicação. Sugere-se que a instruçãofocada-na-forma via reflexão consciente sobre uso de língua parece um recurso pedagógico muito atraente para ajudar aprendizes de ILE a aprender a línguaalvo, assim como a desenvolver sua interlíngua.

PALAVRAS-CHAVE: instrução-focada-na-forma, produção compreensível, lingualização, desenvolvimento da interlíngua, aprendizagem de ILE.

ABSTRACT: This paper examines the concept of languaging (SWAIN, 2006) in the context of form-focused instruction and its role as an important tool for Brazilian foreign language learners, both at advanced level and at elementary level, if linguistic precision is the target. Supported by the Vygotskian sociocultural theory of mind (VYGOTSKY, 1978) and based on studies developed by Swain (2006) in the Canadian context and by Vidal (2003) in the Brazilian scenario, both with advanced learners, the paper shows how Brazilian learners of English of different levels of proficiency and from different instructional realities benefit from languaging - the process of making meaning and shaping knowledge and

*rvidal@nitnet.com.br 
experience through target-language use. A qualitative analysis of both collaborative dialogue and corrective feedback provide evidence for the claim. It is suggested that form-focused instruction via conscious reflection on language use seems to be a very attractive pedagogical resource to help learners EFL to develop their interlanguage further as well as it serves language learning.

KEYWORDS: form-focused-instruction, comprehensible output, languaging, interlanguage development, EFL learning.

\section{Introdução}

Pesquisas na área de aquisição de segunda língua (ASL), ${ }^{1}$ mais especificamente na subárea instrução-focada-na-forma (IFF), apontam para o fato de que a atenção para os aspectos formais da língua-alvo ébenéfica, e até mesmo necessária, para a aprendizagem da língua em foco. Vários estudos, revisados em publicaçōes como as de Spada (1997); Doughty e Williams (1998); Norris e Ortega (2000); Ellis (2001); Long (2007), entre outros, referendam essa alegação. O que não se conseguiu estabelecer ainda, devido à complexidade dos aspectos envolvidos no ensino-aprendizagem de uma língua estrangeira / segunda língua (LE / L2) (LARSEN-FREEMAN, 1997; PAIVA, 2005; LEFFA, 2006), seria qual a maneira mais eficaz de se chamar essa atenção e de se levar aprendizes à internalização, e consequentemente, à aprendizagem dos aspectos formais da língua-alvo com vistas à acuidade linguística.

Estudos desenvolvidos no Canadá, em contexto de programas de imersão de língua francesa, coordenados pela pesquisadora Merrill Swain, do Centro de Línguas Modernas do Ontario Institute for Studies in Education, da Universidade de Toronto (OISE/UT), parecem fornecer subsídios teóricos e pragmáticos com relação ao assunto. Recentemente, Swain refinou o construto produção compreensível (comprehensible output), ${ }^{2}$ mola mestra de suas teorizaçóes e pesquisas (SWAIN, 1985), lançando "lingualização" (languaging) (SWAIN, 2006). Na verdade, não há uma total reformulação do conceito anterior (VIDAL, 2007c), mas uma evolução, um upgrade, uma reinterpretação de sua hipótese inicial, agora no âmbito da teoria sociocultural de aprendizagem de Vygotsky (1978), em vez de dentro de um paradigma do processamento da informação. Por

\footnotetext{
${ }^{1}$ Aquisição de segunda língua (ASL) está sendo usada genericamente, como um campo de estudo, englobando segunda língua (L2) e língua estrangeira (LE).

${ }^{2}$ Produção compreensível é produção que estende o repertório lingüístico do aprendiz na sua tentativa de construir precisamente e apropriadamente a mensagem desejada. (SWAIN, 1985, p. 252; tradução da autora)
} 
lingualização entende-se: "o processo de se construir significado e moldar conhecimento e experiência através da língua. É parte daquilo que constitui a aprendizagem. Lingualizar sobre a língua é uma das formas de se aprender essa mesma língua" (SWAIN, 2006, p. 151; tradução da autora). Em outras palavras, lingualização é o processo de se criar, de se construir significado, e de se moldar conhecimento e experiência ao se usar a língua-alvo com reflexão sobre esse uso e sobre o processo de se tentar expressar o que se deseja na língua-alvo. Acreditam a pesquisadora Canadense, assim como esta pesquisadora, que a lingualização pode levar à aprendizagem da língua em questão. Importante acrescentar é que essa lingualização é realizada via diálogo colaborativo, diálogo para solução de problemas e construção de conhecimento, quer seja o social, com o outro, ou o privado, fala com e para si próprio (VIDAL, 2004), como se pode conferir no trecho abaixo, reproduzido no original.

Languaging $[\ldots]$ refers to the process of making meaning and shaping knowledge and experience through language. It is part of what constitutes learning. Languaging about language is one of the ways we learn language. This means that the languaging (the dialogue or private speech) about language that learners engage in takes on new significance. In it, we can observe learners operating on linguistic data and coming to an understanding of previously less well understood material. In languaging we see learning taking place (SWAIN, 2006, p. 151).

Ao lingualizar sobre uso de língua, aprendizes articulam seu pensamento transformando sua produção em objeto que também passa a ficar disponível para reflexão futura e sujeito a nova avaliação pela lingualização. Desse modo, eles utilizam a linguagem como ferramenta de expressão de suas intenções comunicativas e, ao mesmo tempo, como meio de reflexão sobre essas mesmas intençôes. Em outras palavras, eles raciocinam (preferencialmente) com e / ou por meio da língua-alvo e sobre a língua-alvo. Esse processo, acredita-se, deverá levar ao desenvolvimento e à aprendizagem da língua em questão.

O presente relato, embasado em pesquisas realizadas dentro do Projeto Aprendizagem de Língua Estrangeira em Sala de Aula (ALESA) ${ }^{3}$ tem por

\footnotetext{
${ }^{3} \mathrm{O}$ projeto ALESA é desenvolvido no Programa de Pós-Graduação e Departamento de Letras Estrangeiras Modernas da Universidade Federal Fluminense, sob a coordenação e responsabilidade da autora deste texto. É projeto interinstitucional entre a UFF e a Universidade Federal do Rio Grande do Sul (UFRGS), com a participação de Mestrandos em Letras e alunos do Curso de Especialização em Linguística Aplicada: ensino-aprendizagem de inglês como língua estrangeira da UFF.
} 
objetivo demonstrar que não só alunos de nível adiantado podem se beneficiar do processo de lingualização para aprender inglês como segunda língua, como tem atestado Swain em contexto canadense (SWAIN, 2000; SWAIN; LAPKIN, 2002) e Vidal, entre outros, em contexto de aprendizagem de inglês como língua estrangeira no Brasil (VIDAL, 2003, 2004, 2007a), mas também os de nível mais elementar. Tem, ainda, por objetivo mostrar que essa teorização, além de poder ser benéfica em contexto brasileiro, pode ser pertinente tanto se se lingualizar em língua materna (L1) como em língua estrangeira (LE).

\section{Fundamentação teórica}

A teoria sociocultural da mente, advogada por Vygotsky (1978) para a aprendizagem como um todo, tem recentemente encontrado muitos adeptos no campo da ASL. Ela preconiza que a aprendizagem de um modo geral se dá por meios simbólicos e que a interação social e a privada têm papel fundamental na aprendizagem de uma língua, sendo a própria língua a ferramenta de mediação para a aprendizagem dessa mesma língua (LANTOLF, 2000). Estudos desenvolvidos não apenas no Canadá, como já mencionados, mas também nos Estado Unidos (LANTOLF; APPEL, 1994; DONATO, 1994; DOUGHTY; WILLIAMS, 1998; LANTOLF, 2000) e também no Brasil (VIDAL, 2003, 2004, 2007; BASSI; DUTRA, 2004; LIMA; PINTO, 2007) têm demonstrado o função da interação na aprendizagem de L2 / LE, por meio do que se veio a chamar de diálogo colaborativo, uma das terminologias utilizadas por Swain (2000) para substituir o termo produção, output, requisito necessário, segundo ela, para o desenvolvimento e aprendizagem de uma L2 / LE.

Segundo Swain $(1985,1995)$, o que parece necessário para a aprendizagem de uma L2 / LE é produção na língua-alvo, produção que leve à produção estendida, e não realmente, ou apenas, o insumo compreensível (KRASHEN, 1982), embora não descarte, assim como esta pesquisadora, que o insumo não tenha o seu papel. O que Swain preconiza é que a produção, seja oral ou escrita, exerce papel fundamental na aprendizagem, porque mais facilmente ajuda aprendizes a mudarem de um processamento semântico para um processamento sintático ao tentarem expressar na língua-alvo aquilo que desejam.

Outros papéis foram atribuídos à produção (SMITH, 1978; McLAUGHLIN; ROSSMAN; McLEOD, 1983; SCHACHTER, 1984; LONG; PORTER, 1985; citados em KOWAL; SWAIN, 1997), mas, segundo a hipótese da produção compreensível, a produção na língua-alvo tem três (3) funções: (1) a função da percepção (noticing function) - ao tentar se expressar 
na L2 / LE o aprendiz descobre que não sabe dizer exatamente o que deseja, isto é, ele nota um "buraco" na sua interlíngua (notices the hole) tornando-se consciente de suas limitações, de seu problema linguístico, parcial ou total, o que pode desencadear processos cognitivos que podem gerar conhecimento novo ou consolidar conhecimento prévio; (2) a função da formulação e verificação de hipóteses (bypotheses formulation and testing function) - ao ver que não sabe expressar a mensagem pretendida, o aprendiz procura no insumo, recorre a seus recursos linguísticos internos, a seu interlocutor, ou ainda a outros recursos externos que possam ajudá-lo a preencher a lacuna, fazendo tentativas, lançando hipóteses, para solucionar seu problema linguístico-comunicativo que sua interlíngua não pode manipular sem esforço; (3) a função metalinguística (metalinguistic function or reflective function) - ao produzir e refletir sobre uso de língua, verbalizando sobre seu problema com o outro ou consigo mesmo, o aprendiz pode conseguir preencher a lacuna entre a língua materna e a línguaalvo. Em outras palavras, ao tentar, a partir de uma dificuldade linguística, buscar a solução do problema por meio de metafala, fala sobre uso de língua, o aprendiz (e / ou seu interlocutor) pode ser levado a uma consciência das formas e regras e das relações entre elas fazendo com que ele possa chegar a um entendimento das relações entre significado, forma e função de uma maneira altamente contextualizada. É por meio dessa reflexão que se pode observar o aprendiz notar o que não sabe, e testar hipóteses; é por meio da metafala que se pode observar a aprendizagem como processo; é por meio dessa função reflexiva que os próprios aprendizes podem negociar forma e significado. $\mathrm{E}$ ainda, e utilizando o novo construto, é por meio da lingualização que aprendizes têm a oportunidade de criar novos significados e entendimentos, trabalhando não somente "com" a língua e / ou "por meio" da língua, mas também "sobre" a língua para atingir seus objetivos. Em resumo, ao lingualizar o aprendiz estaria utilizando o próprio alvo dessa aprendizagem como ferramenta comunicativa e como ferramenta cognitiva, permitindo-se aprender e estender sua interlíngua enquanto esse mesmo processo está em desenvolvimento.

A evolução na conceituação de um dos principais construtos da teorização sobre o papel da produção na aprendizagem de línguas sob a ótica da teoria sociocultural - o abrangente conceito de lingualização - parece

${ }^{4}$ Consciência linguística: "conhecimento explícito sobre a linguagem, e percepção consciente e sensibilidade na aprendizagem de línguas, no ensino de línguas e no uso de língua" (SVALBERB, 2007, p. 288, from ALA website; tradução da autora). 
reforçar também a importância da consciência linguística (language awareness, $L A)$ no processo de aprendizagem de uma L2 / LE, corroborando posição há muito levantada por Hawkins (1974, 1999), reconhecido como o "pai" do Language Awareness movement: a reflexão sobre a língua-alvo (nativa ou estrangeira) deveria fazer parte do currículo escolar.

A instrução formal, ou seja, o ensino da gramática, mais recentemente reinventado, ou redescoberto, ou interpretado como tendo um novo recomeço (VIDAL, 2007c) sob a perspectiva da instrução-focada-na-forma (IFF) vem dar conta de metodologias e procedimentos que propiciam a utilização da lingualização como recurso fundamental para se alcançar benefícios na aprendizagem de uma L2 / LE. Esse foco nos aspectos formais abrangeria sintaxe, léxico, ou discurso (WILLIAMS, 2001) e seria ativado por meio de reflexão consciente sobre problemas encontrados na produção da língua-alvo, com o objetivo de tornar-se a fonte propulsora do desenvolvimento da interlíngua e da aprendizagem.

Por motivo de limitação de espaço e também de foco, não será discutida, neste texto, a diferença entre foco na forma e foco nas formas (LONG, 1991), distinção já abordada em vários outros artigos (LONG; ROBINSON, 1998; ELLIS, 2001; LONG, 2007; SPADA; LIGTHBOWN, 2007, no prelo), e inclusive em Vidal (2008, no prelo). Adotar-se-á a interpretação não unânime, vale acrescentar, de Spada (2007), que considera IFF como qualquer esforço pedagógico utilizado para se chamar a atenção dos aprendizes para aspectos formais da língua-alvo de maneira implícita ou explícita dentro de abordagens voltadas para o significado nas quais o foco na língua-alvo pode ocorrer de maneira planejada ou espontânea.

A interpretação de Spada (1997) parece mais abrangente e condizente com as abordagens que privilegiam a consciência linguística (CA) como importante para a aprendizagem e em consonância com a visão de que a lingualização como processo estimula essa consciência e constitui objeto instigante para pesquisa, por ainda não ter seus efeitos totalmente explorados (SVALBERG, 2007). A possibilidade de a instrução poder ser explícita se aplica bem à função reflexiva da produção. Assim, ao lingualizar sobre o uso de língua, por meio de diálogo colaborativo, a partir de percepção de dificuldades linguísticas, aprendizes seriam levados a prestar atenção a como estão expressando sua mensagem e, ao refletir sobre essas dificuldades de produção, tentar solucioná-las por eles mesmos e / ou com a ajuda de seus pares e / ou de feedback do professor em situação de natureza comunicativa. 


\section{Investigações em contexto brasileiro}

Os estudos conduzidos por esta pesquisadora foram desenvolvidos em contexto de ensino de ILE em curso de formação de professores de portuguêsinglês de uma universidade do sudeste do Brasil e já relatados anteriormente em diversas oportunidades (VIDAL, 2003, 2004, 2007a, 2007b). O foco principal da investigação (VIDAL, 2003) foi a questão da precisão linguística em contexto de instrução-focada-na-forma via tarefas comunicativas de conscientização linguística. O objetivo maior foi explorar maneiras de ajudar aprendizes adiantados de ILE a melhorar sua precisão linguística. Desejou-se descobrir o quanto esses aprendizes poderiam conseguir trabalhando sozinhos e / ou em pares, sem a ajuda do professor ou de outras fontes externas de feedback. A triangulação cruzou texto escrito, protocolos verbais (individuais e em dupla) e um questionário semi-estruturado de vinte participantes, para se verificar que tipo de tarefa, com mais ou menos foco explícito na forma, oferecia oportunidade de produção estendida mais eficiente (SWAIN, 1985), mais eficaz; isto é, de produção correta, precisa e adequada depois de o aprendiz ser compelido a fazê-lo. Além disso, queria se observar quais seriam os focos / aspectos de atenção, se os aprendizes solucionavam seus problemas linguísticos sozinhos e / ou em par, se conseguiam articular a razão de suas dúvidas e as soluçôes para elas, e ainda como se apercebiam de seu próprio processo de aprendizagem. Os indícios de que a tarefa de gramaticalização, a que seria o meio termo do contínuo explícito-implícito foco na forma, que partia de palavras e / ou afixos para se construir significado / sentido, na forma de um pequeno texto, demonstrou ser a mais eficiente. Contudo, foram os resultados com a análise do processo, por meio dos "Episódios Referentes à Língua" (ERL) - entendidos como qualquer segmento de protocolo verbal em que aprendizes refletem sobre a língua que estão produzindo, questionam seu uso, se autocorrigem ou corrigem a produção de seu interlocutor - aqueles que pareceram fornecer subsídios valiosos à teorização do importante papel da interação e, mais especificamente, da lingualização, no desenvolvimento e aprendizagem de ILE por alunos brasileiros adiantados. Pela necessidade de esforço para expressar o que se desejava dizer, por meio de diálogo colaborativo consigo mesmo e / ou com o outro, via metafala, esses aprendizes conseguiram muito no seu processo de trabalhar a língua-alvo para desenvolvê-la e "aprendêla". O diálogo colaborativo como meio de construção, coconstrução e reconstrução de conhecimento, como preconiza a teoria sociocultural, realizado por meio de andaimes que atuam na zona de desenvolvimento proximal 
(ZDP), ${ }^{5}$ aliado à hipótese da produção compreensível e, em última análise, à lingualização como construto, parece ter fornecido evidências de sua importância no campo da aprendizagem de LE em contexto brasileiro pela investigação conduzida por esta pesquisadora. Abaixo destaco dois episódios que ilustram o papel da lingualização, não só por meio de e sobre a língua-alvo mas também por meio da L1, no desenvolvimento da interlíngua dos participantes:

\section{Episódio 1 (Pensar alto (PA))}

(PA, Tarefa 3, Aluno 2, linhas 62-70)

..... como é que eu vou dizer que começou a tempestade? However the weather suddenly changed however the the weather.... however the weather suddenly changed and hum hum and then não sei se isso é certo mas vou chutar and then a storm se formou? não and the a storm se formou? Isso é bem aportuguesado ridículo mas vou botar assim mesmo was formed. ..... and a storm was formed hum and a storm was was formed. However the weather suddenly changed and a storm ..... gente isso não existe ..... however the weather suddenly changed and ..... started? .... however the weather suddenly changed and the storm started, storm started tá muito próximo .... begun began. However the weather suddenly changed and the storm began.

No Episódio 1, protocolo de pensar-alto, A2 não se recordava como seria "começou a tempestade" em inglês. Ela começou com "the weather suddenly changed" e tentou completar com "and then a storm se formou", mas esse "se formou", traduzido a princípio na íntegra por "was formed" não a satisfez. Aliás, A2 comenta que "é bem aportuguesado ridículo", e a princípio ia deixar assim mesmo. Como a forma "ridícula" ficou martelando na sua consciência, ela arriscou "started?", com entoação de pergunta. Ainda não satisfeita, finalmente lançou "began" e finalmente aceitou e, com ênfase, disse "began", solucionando seu problema. O episódio mostra o esforço que a aprendiz fez consigo mesma para construir o significado desejado: ao ser levada a refletir sobre sua produção linguística, essa produção passou a ser seu objeto de análise e, ao mesmo tempo, a forma de como expressar sua mensagem.

5 ZPD: o "local" metafórico no qual um aprendiz é capaz de desempenho de nível mais alto porque há apoio da interação com um interlocutor. Ou seja, distância entre o nível de desenvolvimento real, que se costuma determinar por meio da solução independente de problemas, e o nível de desenvolvimento potencial, determinado por meio da solução de problemas sob a orientação de um adulto ou em colaboração com companheiros mais capazes (MITCHELL; MYLES, 2004). 
No episódio citado abaixo, de trabalho em dupla, A6 e A7 estão lingualizando sobre a difícil escolha entre o passado simples, o passado contínuo, o presente perfeito e o presente perfeito contínuo. Ao levantar o problema, A7 tenta usar e explicar o significado do presente perfeito contínuo com uma frase e o comentário "because I still study there" para justificar esse uso, mas estava insegura. Seu par, A8 também disse ter o mesmo problema com a utilização desse tempo verbal e sugeriu o passado simples para o contexto em questão - uma referência aos seus estudos de inglês - em razão ao tempo do início desses estudos, o que $\mathrm{S} 7$ concordou. Mas, na realidade, eles estavam entre o passado simples e o presente perfeito, em razão de $\mathrm{A} 7$ ter passado para três Universidades e ter escolhido uma, isto é, na dúvida entre "chose" ou "have chosen". Até o presente "choose" foi mencionado, mas depois da ajuda recíproca e de raciocinar que se o contexto se referia ao passado, como se pode observar no turno 053 de A8: "this sentece I'm saying past I mean", e logo depois no turno 060 de A7: "You know what I mean? I have chosen, it's past but if I have to choose now I would still choose this one. So I have chosen, I still choose or I chose it's already past. You know what I mean?", e ainda no turno 062 de A7: Yeah, I passed I passed" decidiram pelo presente perfeito. Logo depois, há dois comentários bem interessantes: turno 065 A8: "Yeah, you need to write a lot to solve these problems" 066 A7: "The person who will correct will explain you the right things to be done because I think if you don't write it you'll never learn.... cause books you know don't keep you just don't give information" (ênfase da autora), que corroboram a crença de que é necessário esforço, empenho para se progredir na aprendizagem de uma L2, e que, ao produzir para tentar solucionar o que não sabem ou não sabem parcialmente, concomitantemente à reflexão sobre a lacuna, pode-se chegar à produção estendida.

Episódio 2 (Trabalho em dupla [PW])

(PW, Tarefa1, Alunos 6-7, turnos 040-71)

040 A7: I was afraid of how to use the Past Perfect Continuous. I have 041 A8: Past Continuous.

042 A7: I was afraid of only only using the Present Perfect Continuous because I have been studying, because I still study there. I have been studying English at the university for one year. I didn't know....

043 A8: I have the same problem; just Past Simple. I started studying English when I was, it took me a long time to decide.... when I was seventeen I wanted

044 A7: I used Past Simple or Simple Past.

045 A8: Yeah, we use it more because hum in my case I always put hum I started studying English when I was $\mathrm{x}$ with a time, with a 
reference of time so.... I couldn't and I was trying to, to, to think of sentences to to use hum Present Perfect but I couldn't just in the end. 046 A7: Yeah. When I started talking about myself [laughter] I only used Simple Past.

047 A8: Yeah, but in some cases I don't know, I still don't know when I used hum Present Perfect, when I use Past Simple. I still have some doubts. 048 A7: Yeah, sometimes I have doubts.

049 A8: Yeah, some things are very easy, but others

050 A7: There was one sentence here I didn't know what to do. Hum I'm trying for example "But I choose or have chosen [she wrote choosen, but pronounced chosen] the first one." For example the first one, let me read "Actually I passed for three universities but I have chosen [she wrote choosen] the first one" or but I chose the first one? 051 A8: But I chose, yes?

052 A7: Chose? Choose? I put I have chosen [she wrote choosen] but I'm not sure.

053 A8: But I have chosen or chose. Xxx Não não x I'm not saying this sentence I'm saying past I mean, xx choose, chose, chosen.

054 A7: But yes, I don't know.

055 A8: I don't know.

056 A7: Yes, I don't know

057 A8: I have already chosen

058 A7: But nowadays if I have to choose I still choose the first one 059 A8: Yeah, because

060 A7: You know what I mean? I have chosen, it's past but if I have to choose now I would still choose this one. So I have chosen, I still choose or I chose it's already past. You know what I mean?

061 A8: Yeah, I know what you mean. I don't know. Yeah. That's one of $\mathrm{x}$ ok, I don't know because in fact if for instance you wrote... I think the the form tense... The form tense you used was Past Simple, wasn't it? 062 A7: Yeah, I passed I passed

065 A8: So I don't know because you said you passed you chose or because of the reason you gave me I chose that's I don't know just.... that's ok.

064 A7: Yeah, $x$ x

065 A8: Yeah, you need to write a lot to solve these problems.

066 A7: The person who will correct will explain you the right things to be done because I think if you don't write it you'll never learn.... cause books you know don't keep you just don't give information. 067 A8: Yeah.

068 A7: Explanations to clear your mind 069 A8: It's not really useful.... if you don't try, don't practice.

070 A7: Yeah, we have to practice a lot [laughter].

071 A8: [laughter] 
A seguir passo a reportar estudos desenvolvidos por alunos de Especialização e de Mestrado em Linguística Aplicada, ensino-aprendizagem de língua inglesa, da Universidade Federal Fluminense (UFF), que de diferentes formas, e com aprendizes de níveis e subcontextos diversos, também investigaram o papel da lingualização na aprendizagem de ILE de seus alunos.

Bastos (2005) trabalhou com treze (13) crianças que frequentavam o pré-escolar no Rio de Janeiro e que tinham aula de ILE cinco dias por semana, durante três horas e meia todos os dias. Uma oportunidade única e sui generis no Brasil. Durante esse tempo, os professores seguiam uma rotina com atividades nas quais o foco não era na forma per se, mas em qualquer outra coisa, dentro de um tema escolhido a cada ano letivo. Por exemplo, quando o tema era países ao redor do mundo, as atividades eram focadas nas diferentes culturas, animais, clima, etc. Além disso, trabalhavam-se regularmente bons hábitos de higiene, compartilhamento e cooperação. Todos esses momentos, disse a professora da turma, e também pesquisadora, eram excelentes para se promover interação e comunicação, criando um ambiente favorável para a aquisição ${ }^{6} \mathrm{da}$ língua estrangeira. As salas eram bem decoradas e convidativas visualmente. Havia biblioteca, podiam assistir a filmes e também havia uma salinha para se produzir artesanato. Além das salas de aula, os alunos tinham acesso a um pátio, com caixa de areia e um pequeno jardim, um verdadeiro luxo para os nossos padrões. Nesse contexto, as crianças eram desafiadas a todo o momento e guiadas a se comunicarem espontaneamente e com criatividade na língua inglesa.

Foi nesse contexto, de muita espontaneidade comunicativa, que Bastos observou o seguinte diálogo colaborativo:

Extrato 1 (Atividade social / língua: Jogo de memória)

Teacher: It is your turn now, Luca.

(Luca turns up a yellow train car)

Teacher: Hey! What is this?

Luca: Train

David e Juliano: Yellow train!

Teacher: Yes, it's a yellow train. And now where is the other one? Do you know?

(Lucas turns up another card: "Ah, não! É a bicycle red."

Davi: "Não. Red bicycle!"

Luca: Red bicycle.

\footnotetext{
${ }^{6}$ Aprendizagem e aquisição estão sendo usados intercambiavelmente, sem as implicações Krashenianas.
} 
O que se pode notar no Extrato 1 é que aprendizes crianças estão engajados num jogo de memória. Nesse jogo, observa-se que Luca coloca o adjetivo depois do substantivo e Davi, que tinha se apercebido da posição certa, ajuda o amigo, fornece o andaime, dizendo a frase correta, que é logo incorporada por Luca.

Eainda:

Extrato 2 (Atividade língua: "How do you say... in English?”, Jogo de advinhação)

Juliano: How do you say "papel” in English?

Sofia e Guilherme: Paper!!

Juliano: How do you say "bobo" in English? $\mathrm{Ha}, \mathrm{Ha}, \mathrm{Ha}$ !!!

Guilherme: Fabiane! (to the teacher) How do you say "bobo" in English? "Bobo" in English?

Fabiane: Silly.

Children: Silly! Silly! Silly! Ha, Ha, Ha!

(Nesse momento todos mudam seu interesse para outras atividades, mas Juliano continua brincando o jogo de adivinhação mais um pouco enquanto desenha)

Juliano: How do you say "flor" in English? (Ele desenha uma flor e diz para ele mesmo: flower. Depois faz a mesma coisa com water e bee).

No Extrato 2, aprendizes espontaneamente usam a expressão "How do you say... in English?" bastante utilizada nas atividades ao longo do curso, como declarou a professora, e imediatamente fazem uso da palavra objeto do questionamento. Nota-se que Juliano continua por ele mesmo a utilizar a fórmula e a reemiti-la para si mesmo com outras palavras enquanto desenha as figuras que as representam. Parece evidência de que ele utiliza sua fala privada, que continua produzindo enquanto continua o jogo para, e aqui se acredita, inconscientemente, internalizar as palavras com as quais se deparava.

Sem a oportunidade da interação, do diálogo colaborativo, em última análise da lingualização, talvez tivesse sido impossível que alguma coisa do gênero pudesse acontecer. Vale ressaltar que o interesse pela língua, por como expressar a mensagem, partiu das próprias crianças, como decorrência do desenho da atividade. Logo outras crianças se juntaram e, cada vez que descobriam uma nova palavra engraçada, começavam a rir, a brincar uns com os outros, mostrando que, mesmo lingualizando, isso pode ser divertido.

Wille de Souza (2006) trabalhou com 162 alunos iniciantes (cinco turmas de $5^{\text {a }}$. série), entre 10 e 12 anos de idade, de ILE de uma instituição pública federal do Rio de Janeiro, com o objetivo de observar se alunos mais jovens e iniciantes percebem a retroalimentação corretiva implícita (acentuação do 
insumo) acerca de texto escrito produzido em pares, se tiram proveito do diálogo colaborativo em L1 durante a atividade, e se mantêm o aprendizado durante uma tarefa de reconstrução dessa produção escrita. Esses alunos tinham aula de língua inglesa, com ênfase na leitura, duas vezes por semana durante quarenta e cinco minutos cada.

Os instrumentos para a realização da investigação foram uma atividade de produção escrita (carta descrevendo a si próprios) em colaboração, embora cada um mantivesse a sua versão individual (a qual se daria uma nota que contaria como avaliação oficial do período), a reescrita dessa produção depois do text / input enhancement pela professora da turma e também a pesquisadora, e ainda um questionário, aplicado imediatamente após a reescrita, que teve a função de retrospecção ou stimulated recall adaptado. Todo o procedimento levou 3 aulas, e pelo expressivo número de alunos por turma, de 30 a 35, os diálogos colaborativos não foram gravados e nem se pode realmente fazer um stimulated recall genuíno. Na verdade, o que se examinou foi o produto final. O processo foi analisado indiretamente por meio das respostas ao questionário em L1, português. Essas estratégias muitas vezes precisam ser utilizadas, mas nem por isso a atividade / pesquisa deixa de alcançar seu objetivo. Abaixo, transcrevo o questionário utilizado (FIG. 1).

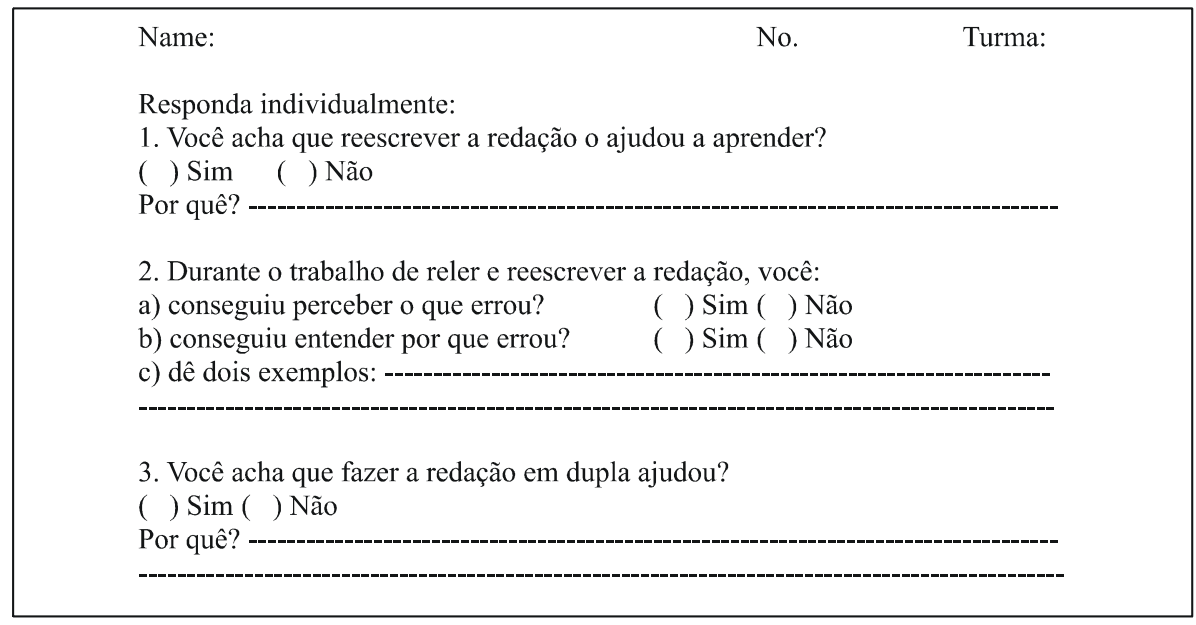

FIGURA 1 - Questionário 
Com relação às respostas ao questionário, eà pergunta 1 , a maioria (157) respondeu que sim porque ajudou a perceber e entender os erros (70), a "treinar" a língua (46), a corrigir os erros (22) e a aprender com eles (10), a ajudá-los a lembrar (8), e que foi uma chance de trabalhar como um time (apenas 1). Com relação à pergunta 2, 148 responderam que notaram seus erros e 135 que entenderam porque tinham errado. Com relação aos tipos de erros, ou seja, aos aspetos focados (Aspectos de interesse ou Episódios relacionados à língua), eles foram variados, de ortografia (91), estrutura (22), pontuação (22), uso do artigo (16), uso do verbo (10), ordem de palavras (9), não conhecimento da palavra que queria usar (9), interferência da L1 (9), entre os mais frequentes. Finalmente, com relação à pergunta 3, a maioria (147) respondeu que o trabalho em par ajudou porque: (a) puderam discutir as dúvidas com os parceiros (61); (b) porque puderam ajudar e receber ajuda (36); (c) porque o par ajudou a fazê-los perceber os erros (17); (d) porque puderam falar sobre o que estavam escrevendo (15); (e) porque "duas cabeças pensam melhor do que uma" (11); (f) porque tornou-se mais fácil entender dessa maneira (7); (g) e apenas (1) disse que trabalhar em dupla tinha ajudado para variar. Dos 14 que responderam que trabalhar em dupla não ajudou, a alegação mais frequente (4) foi que o par na verdade não ajudou e / ou porque nem ele nem o par se ajudaram mutuamente, ou ainda (2) porque não prestaram a devida atenção à atividade e (2) que cada um, na verdade, tinha trabalhado sozinho. Apenas (1) disse que o par não sabia para ajudá-lo, ou não pediu ajuda (1) ou ainda (1) que não gostava de trabalhar em dupla.

Devido ao exposto, o que se pode depreender é que esses jovens alunos iniciantes de ILE conseguiram perceber seus erros, corrigi-los, reconhecendo a positividade do trabalho em dupla. Tudo isso estaria corroborando a alegação de que ao tentar produzir na língua-alvo, refletir sobre ela, e procurar e receber algum tipo de feedback, aprendizes podem notar suas deficiências e tentar sanálas para seu crescimento linguístico, como advoga a hipótese da produção compreensível.

Moreira (2006) também trabalhou com turmas de uma escola pública da cidade do Rio de Janeiro, só que de $7^{\mathrm{a}}$. série. O objetivo da pesquisa foi também o de examinar a capacidade dos aprendizes de ILE em perceber as lacunas existentes na sua interlíngua, por meio do processo de noticing durante atividade de autocorreção textual, por meio de reflexão conjunta sobre a forma, realizada em diálogos colaborativos. As perguntas que motivaram o trabalho foram: (1) aprendizes de língua inglesa de dentro do contexto de escola regular 
e com pouco conhecimento da língua-alvo seriam capazes de perceber e corrigir inconsistências linguísticas em sua produção escrita de forma autônoma?; e (2) o diálogo colaborativo auxilia o aluno a perceber tais inconsistências mais efetivamente? A tarefa usada para a coleta de dados foi a confecção de cartôespostais escritos e enviados através de websites, previamente selecionados pela professora, também a pesquisadora, e dividia em três etapas:

1a. etapa: após instrução formal sobre os tempos verbais Simple Present, Simple Past e Going to Future, os alunos escreveram um cartãopostal virtual de um local que supostamente tivessem visitado e enviaram para sua professora. Para tal, foram utilizados alguns websites que disponibilizam cartões desse tipo. A atividade foi realizada em pares e alunos com maior proficiência na língua-alvo foram incentivados a trabalhar com alunos de menor proficiência. Todos receberam informação do que deveria constar do cartão: impressóes sobre o local, clima, pontos turísticos visitados e planos para futuras visitas. Os alunos também deveriam fazer perguntas ao recebedor do cartão, usar os tempos verbais acima citados e estavam autorizados a consultar o livro didático ou seus próprios colegas em caso de dúvidas quanto ao léxico e a estruturas gramaticais.

2a . etapa: após receber os cartôes via Internet, a professora imprimiu cópias e sublinhou palavras, frases o orações que contivessem algum tipo de inconsistência gramatical ou lexical (técnica da "salientação"). Após receberem tais cópias, os alunos foram instruídos a fazer a correção dos textos com o colega com o qual eles haviam feito a primeira versão do cartão. Foram também aconselhados a discutir com seus pares sobre seus problemas linguísticos para tentar resolvêlos. A consulta ao livro didático foi mais uma vez autorizada. A professora monitorou o trabalho, sem interferir na correção, e informou que a segunda versão do cartão, corrigida por eles próprios, seria exposta em uma mostra pedagógica no final do ano letivo.

3a . etapa: após a entrega da segunda versão do trabalho, os alunos preencheram um questionário no qual opinaram sobre dois aspectos da atividade: o trabalho em pares e a autocorreção.

Segundo a pesquisadora, vale acrescentar que, aliada à informação de que seus textos seriam expostos em posterior mostra pedagógica na escola, a tarefa 
fazia parte da avaliação trimestral da disciplina, o que provavelmente motivou os participantes a aperfeiçoar seus textos.

Os resultados (depois da análise do uso adequado dos tipos de erro: tempos verbais em foco, uso de vocabulário básico sobre o tema em questão, e ortografia) apontaram também, de forma muito positiva $(64,8 \%, 91 \%$ e $77 \%$ por tipo de erro corrigido, respectivamente), para o fato de que, por meio da autocorreção de sua produção escrita e do diálogo colaborativo com seus pares, os alunos da referida série (23 pares) demonstraram ser capazes de corrigir as inconsistências linguísticas ocorridas em seus textos de maneira autônoma e consciente. Nesse estudo, diferentemente do de Wille de Souza (2006), os aprendizes puderam perceber e corrigir mais efetivamente seus erros de ortografia e de léxico, talvez porque estavam mais atentos à sua produção na segunda fase da tarefa, procurando suas respostas também no próprio material didático. Esse resultado vem corroborar o estudo de Williams, de 1999, que aponta para o fato de que aprendizes com menor nível de proficiência se concentram mais frequentemente no aspecto lexical de sua produção, ratificando a ideia de que aprendizes iniciantes se atêm mais ao significado do que à forma. Com relação ao tempo e a formas verbais, os alunos pareceram ter tido mais dificuldade para perceber suas inconsistências, mesmo tendo ao seu alcance os mesmos recursos: seus pares e o material didático. Tal dificuldade poderia ser atribuída à complexidade do tópico gramatical em questão. Mesmo assim, o percentual encontrado $(64,8 \%)$ mostra que eles conseguiram perceber e corrigir muitos de seus erros quando refletiam sobre sua própria produção.

Com relação ao questionário aplicado, pode-se inferir a percepção dos alunos quanto à importância do trabalho em par e da autocorreção no processo de construção do conhecimento sistêmico de uma língua estrangeira "Discutindo e pensando a gente pode corrigir os erros" - $95 \%$ dos alunos relataram que a modalidade didática (autocorreção) aplicada proporcionoulhes oportunidade de perceber e corrigir seus erros; $81 \%$ declararam que o fato de a professora ter apenas marcado os erros, em vez de corrigi-los, os ajudou a ter mais consciência desses erros, e desse modo, aprender mais efetivamente. Em relação ao trabalho em pares, $74 \%$ dos alunos declararam ter discutido com seu par sobre os erros apontados e, deste grupo, 94,5\% afirmaram que esse tipo de discussão os ajudou a chegar a uma versão mais elaborada do cartão. Apenas $12 \%$ afirmaram que o trabalho em dupla não os ajudou.

Os relatos dos alunos, bem como o produto final da tarefa, parecem demonstrar a relevância da produção linguística no processo de aprendizagem 
de uma LE, confirmando mais uma vez os postulados da produção compreensível. A análise dos resultados desta pesquisa indica que a reflexão sobre a produção linguística, por meio do processo de lingualização, também em L1, pode ser um primeiro passo para a ampliação da interlíngua do aprendiz, desígnio final da instrução-focada-na-forma. Pena, mais uma vez, que os diálogos colaborativos não puderam ser gravados, devido ao número de participantes e da atividade ter sido conduzida em uma sala de aula genuína.

O estudo de Figueiredo (2006), um piloto para a sua dissertação de Mestrado, teve por objetivo investigar o papel do noticing e a efetividade / eficiência da reformulação ${ }^{7}$ como meio de retroalimentação corretiva, tendo em vista uma tarefa de produção escrita em três estágios. A tarefa em questão era semelhante à utilizada por Qi e Lapkin (2001), só que em uma classe genuína e com a articulação da aceitação ou não da reformulação por escrito (motivo: dificuldade de gravação da interação). Na primeira, os pares deveriam (após uma sessão warm-up que todos fizeram juntos para compreender bem a atividade) construir dois diálogos após receberem apenas content words, marcadores e alguns afixos. Na segunda, uma semana após a produção da primeira versão, eles foram instruídos a comparar sua produção com uma versão reformulada da primeira, a discutir / dialogar na língua-alvo (TL) sobre as mudanças propostas e a tomar nota do que haviam observado de diferente, tentando chegar a explicações do porquê dessas mudanças propostas, isto é, articular por escrito, também em TL, o porquê das inconsistências linguísticas notadas / percebidas e as razões para as modificaçōes. Na última etapa, também uma semana depois, os participantes receberam os dois textos, a versão original e a reformulada, e deveriam reescrever seus diálogos face às alteraçōes propostas. Esta última etapa foi feita individualmente. As perguntas de pesquisa foram: (1) O que é que aprendizes de ILE notam ao comparar seus textos com uma versão reformulada desses mesmos textos?; (2) Como é que esse noticing está relacionado com melhora / progresso em versão final de seu produto / texto escrito depois da reformulação?

Os participantes eram quatro alunos adultos, três mulheres e um homem, de nível intermediário / intermediário-avançado, de uma escola de línguas da cidade do Rio de Janeiro. Tinham aulas de língua inglesa aos sábados,

\footnotetext{
${ }^{7}$ A técnica da reformulação consiste em reescrever (idealmente por um falante nativo) o texto do aprendiz, mantendo o conteúdo mais fielmente possível e alterando as inconsistências linguísticas.
} 
por três horas, e o livro texto tinha, ao final de cada unidade, uma etapa que consistia numa figura sobre a qual os alunos deveriam, em pares, construir um diálogo, oralmente ou por escrito, utilizando as estruturas e o vocabulário trabalhado.

Com relação à primeira pergunta, pareceu claro que os aprendizes foram capazes de observar as diferenças entre os dois textos. Além disso, conseguiram chegar a uma explicação correta para a maioria dos erros, embora a língua (ILE) que utilizaram na articulação / argumentação dos problemas não fosse totalmente precisa. Por exemplo:

\begin{tabular}{|l|l|l|}
\hline \multicolumn{1}{|c|}{ Original sentences } & Reformulated sentences & \multicolumn{1}{|c|}{ Explanation } \\
\hline $\begin{array}{l}\text { "I think people need an } \\
\text { authoritative an authoritative } \\
\text { government to avoid abusing } \\
\text { of theedom we have" }\end{array}$ & $\begin{array}{l}\text { "I think people need an } \\
\text { authoritative government to } \\
\text { avoid abusing the freedom } \\
\text { they have" }\end{array}$ & $\begin{array}{l}\text { The verb abuse is not } \\
\text { followed by "of" } \\
\text { They ... refers to people }\end{array}$ \\
\hline $\begin{array}{l}\text { "It depends the circumstance } \\
\text { of the crime" }\end{array}$ & $\begin{array}{l}\text { "It depends on the } \\
\text { circumstances of the crime" }\end{array}$ & $\begin{array}{l}\text { We have to use on after } \\
\text { depend }\end{array}$ \\
\hline $\begin{array}{l}\text { "If happens a serious criminal } \\
\text { the guilt deserves to kill" }\end{array}$ & $\begin{array}{l}\text { "If the crime is very serious, } \\
\text { the criminal deserves to be } \\
\text { killed" }\end{array}$ & $\begin{array}{l}\text {... criminal is the person } \\
\text { and the criminal deserves } \\
\text { to be killed not to kill }\end{array}$ \\
\hline $\begin{array}{l}\text { "I guess we have to agree to } \\
\text { disagree" }\end{array}$ & $\begin{array}{l}\text { "I guess we'll have to agree to } \\
\text { disagree" }\end{array}$ & $\begin{array}{l}\text { We'll - it's not a correct } \\
\text { expression }\end{array}$ \\
\hline
\end{tabular}

FIGURA 2

Releva notar, contudo, que se tenha encontrado nos dados algumas poucas ocasiōes em que não conseguiram perceber seus erros e nem explicar corretamente as inconsistências (cf. FIG. 3 abaixo):

\begin{tabular}{|l|l|l|}
\hline \multicolumn{1}{|c|}{ Original sentences } & \multicolumn{1}{|c|}{ Reformulated sentences } & \multicolumn{1}{c|}{ Explanation } \\
\hline $\begin{array}{l}\text { "If happens a serious } \\
\text { criminal the guilt deserves } \\
\text { to kill" }\end{array}$ & $\begin{array}{l}\text { "If the crime is very serious, the } \\
\text { criminal deserves to be killed" }\end{array}$ & $\begin{array}{l}\text { Guilt is a noun, criminal is } \\
\text { the person and the criminal } \\
\text { deserves to be killed not to } \\
\text { kill }\end{array}$ \\
\hline $\begin{array}{l}\text { "I think it's wrong to take } \\
\text { anyone's life" }\end{array}$ & $\begin{array}{l}\text { "I think it's wrong to take a } \\
\text { life" }\end{array}$ & $\begin{array}{l}\text { Take a life - we have to use } \\
\text { take people's life or take } \\
\text { someones life }\end{array}$ \\
\hline
\end{tabular}

FIGURA 3 
No primeiro exemplo (FIG. 3), parece que os aprendizes não identificaram realmente o problema, e embora guilt seja um substantivo, a explicação não foi condizente com o erro. Eles também não perceberam a utilização da vírgula depois de oração introduzida por if. No segundo, embora parecessem perceber que a frase utilizada não estava apropriada, os aprendizes não entenderam que to take a life deveria ser a estrutura a ser utilizada.

Com relação à segunda pergunta de pesquisa, dois dos participantes (F2 e F3) do sexo feminino pareceram ter tirado bom proveito da reformulação e do diálogo colaborativo, uma vez que nas suas versões finais cometeram menos erros. F1 continuou com alguns erros da versão inicial e M1 não compareceu a esta última etapa. De qualquer forma, esses pouco dados parecem também revelar alguma evidência de que algum tipo de instrução-focada-na-forma é benéfica para a precisão linguística e que atividades que levem aprendizes a notarem suas deficiências são proveitosas, assim como a reflexão sobre seus problemas linguísticos. Contudo, na interpretação do pesquisador, a intervenção do professor mais ativamente durante o processo de noticing e também durante a interação, quando da discussão dos problemas, poderia ser ainda mais enriquecedora para o processo de desenvolvimento da interlíngua.

Seba (2006) desenvolveu, também como piloto para sua dissertação de Mestrado, um estudo de caso que teve como objetivo investigar como a interação negociada em L1 com consciente foco na forma por meio de diálogo colaborativo aumenta a compreensão de textos autênticos em ILE. O que parece interessante ressaltar é que o estudo, assim como o de Swain e Lapkin (2002), parte da produção para a compreensão, e não o contrário, como de costume.

Foram duas as perguntas de pesquisa: (1) Aprendizes de ILE, ao escrever um texto em inglês colaborativamente, lingualizam em L1 sobre forma e significado?; (2) Se aprendizes lingualizam em L1 sobre forma e significado da L2, como é que isso os ajuda a compreender um texto escrito em inglês?

Os participantes desse pequeno estudo foram quatro voluntários (dois homens e duas mulheres), alunos avançados de Inglês Instrumental; i.e., de inglês para fins específicos (IFE), de um curso particular de inglês em Vitória, Espírito Santo, Brasil. O objetivo do estudo era desenvolver a habilidade leitora desses aprendizes para que pudessem prestar exame de ingresso para uma faculdade particular. Esses aprendizes tinham aula de IFE três vezes por semana, durante duas horas.

A tarefa colaborativa teve várias etapas: (1) Pré-escrita: esta etapa consistiu numa discussão para ativar o conhecimento esquemático dos participantes e 
aguçar seu interesse pelo assunto em questão. Foi-lhes apresentado um diagrama relacionado ao tópico escolhido e lhes foi pedido predizer a informação; (2) Tarefa escrita: os quatro participantes, em pares autoescolhidos, foram instruídos a organizar frases em ordem apropriada e combiná-las para formar um parágrafo. Depois foi pedido a eles que organizassem os parágrafos em ordem adequada formando um texto completo. Trabalhavam sempre em dupla, articulando oralmente as suas observações e dúvidas. Podiam utilizar o dicionário, mas não podiam pedir ajuda ao professor, que ficou na sala observando e tomando notas que poderiam ser utilizadas mais tarde para análise; (3) Leitura, Percepção e Reescrita: os aprendizes, ainda em pares, receberam seus textos de volta e a versão original do texto-alvo. Eles foram instruídos a ler atentamente os dois textos, e tentar perceber as diferenças. O próximo passo foi reescrever suas composições, fazendo as correções necessárias, também observando o feedback do par. Não houve intervenção da professora / pesquisadora nessa fase também; (4) Exercício de Compreensão de Texto (leitura): para se verificar se a interação negociada durante a produção do texto escrito em colaboração melhorou a habilidade leitora, os alunos leram o texto original mais uma vez e responderam perguntas de interpretação do texto; (5) Relatório de Avaliação: finalmente, os quatro participantes foram convidados a escrever um relatório, avaliando a experiência do trabalho de colaboração e a sua compreensão do texto.

O diálogo colaborativo em L1 foi analisado qualitativamente, levandose em consideração os "Episódios Relacionados à Língua" (ERL) (SWAIN; LAPKIN, 1995; KOWAL; SWAIN, 1997) como ponto de partida. Embora se tenha encontrado episódios em que os participantes não conseguiram resolver o problema adequadamente, encontraram-se também vários nos quais a solução foi alcançada: ou com a lembrança de conhecimento prévio, ou com construção de conhecimento novo, ou pela percepção da diferença entre a interlíngua e a língua-alvo, como pode se observar nos episódios a seguir.

Episódio 1: Etapa 2 (escolha de palavra)

Gloria: The epidermis is a tough protective layer what contains melanin. Ficou bom assim? É "what" mesmo, não é? Que - acho que é.

Mark: Mas "what" é "o que" - "what are you doing?"

Gloria: Então, como é "que"?

Mark: Acho que é "that".

Gloria: "That"? ah! É mesmo!!! Tonta! "Here is the book that I bought for you" - lembra dessa frase da lição?

Mark: Também pode ser " $w h o$ ", mas só se for para "gente".

Gloria: Tá certo. Somos 'fera' mesmo!!! 
No episódio acima, Gloria une as frases com what. Como estava insegura, ela se utiliza da tradução e aí parece achar que estava correto. Mark, por sua vez, ativando seu conhecimento prévio, questiona o uso de what no contexto em questão e sugere that. Gloria então tem a percepção da diferença e se lembra do que havia aprendido antes via livro-texto. Mark lembra o uso de $w$ ho. Gloria concorda e fica feliz de eles terem resolvido o problema.

O episódio que se segue, o problema é a pronúncia da palavra pleasant, por parte de Mark. Imediatamente Gloria, embora não muito segura, oferece ajuda, e Mark aceita. O feedback estava correto.

Episódio 2, Etapa 2 (pronúncia)

Gloria: Vamos ler tudo agora para ver como ficou.

Mark: Tá bom (lendo alto) "painful and ple..." como é que se pronuncia isso?

Gloria: Acho que é /plezntl

Mark: |pleznt/?

Gloria: É.

Mark: $\mathrm{O}$. Painful and pleasant (corrigindo sua pronúncia).

No episódio 3, Mark e Gloria consideram a possibilidade de unir frases, por reconhecer que devem tentar escrever de uma forma mais elaborada. Nesse caso a sugestão foi de utilizar vírgulas ou então de usar and. Ambos concordam.

Episódio 3, Etapa 2 (união de frases)

Mark: Nessas frases tem muito "the skin". Não podemos escrever assim. Parece parágrafo de criança. Vamos juntar.

Gloria: Coloca vírgula.

Mark: Nas não podemos encher de vírgulas ... vamos colocar "and" também.

Gloria: Tá. Vê se ficou bom assim. (lendo em voz alta)

Mark: Acho que está certo. Agora vem a 5 e depois a 6. Pronto. Terminamos o primeiro parágrafo.

Nos episódios que se seguem, Mark e Gloria conseguem perceber as diferenças entre seu texto e o texto original. Em alguns momentos, decidem alterar o texto produzido por eles, mas em outros mantêm a sua versão, dando sinal de sua autonomia como aprendizes, de sua agentividade. 
Episódio 4, Etapa 3 (segundo dia) (forma)

Gloria: Olha, a gente podia ter escrito assim! Ia ficar bem melhor... Ao invés de colocar ponto, a gente podia ter usado o verbo igual a português: cobrindo...

Mark: Vamos consertar então o nosso texto. Copia aí...

Episódio 5, Etapa 3 (segundo dia) (forma)

Mark: Olha agora. Estranho ... por que aqui tem "ing”? Não é "servindo" ..." In addition to" não quer dizer "além de"? Não se diz "além de servindo"...

Gloria: Pode ter sido erro de digitação. Sei lá... Acho melhor deixar o nosso como está. Depois a gente pergunta pra professora. Acho que do jeito que fizemos também está bom. Não precisa mexer.

Episódio 6, Etapa 3 (segundo dia) (forma)

Mark: Olha só! "ing” de novo. Aqui o sentido é igual ao primeiro: "each providing" - aqui, está certo: cada um fornecendo...

Gloria: Viu? Podemos usar o "ing" pra juntas as frases. Fica até mais bonito. Vou consertar o nosso.

Mais uma vez, os dados mostram que, ao trabalhar em conjunto nesse tipo de tarefa, os aprendizes espontaneamente se engajaram em diálogo que mediou sua aprendizagem. Por meio da produção com diálogo colaborativo, os aprendizes foram capazes de perceber suas dificuldades linguísticas, como preconiza a hipótese da produção compreensível, e de tentar encontrar meios para solucionar seus problemas colaborativamente. Ao verbalizar sobre suas dificuldades com a interação social, os aprendizes tiveram a oportunidade de refletir sobre elas, analisá-las e entendê-las melhor. $\mathrm{O}$ andaimento durante a interação parece ter propiciado o desenvolvimento da interlíngua.

A atividade de compreensão do texto (etapa 4) foi realizada com sucesso. Ao completar uma tabela, em Português, organizada para esse fim, os alunos demonstraram que tinham entendido o texto inteiramente. $\mathrm{O}$ relatório final (etapa 5) revelou que eles gostaram de trabalhar em dupla e estavam felizes com o que tinham conseguido alcançar sem a ajuda do professor.

O que esse pequeno estudo demonstrou também e que merece nota é de que se pode partir da produção para a compreensão, em contrapartida ao que sempre se pensou e fez, mas, sobretudo, que o tipo de atividade utilizada permitiu a esses alunos de IFE não só compreender melhor o texto em foco, mas, acima de tudo, acreditar em suas potencialidades para aprender uma língua estrangeira. 


\section{Considerações finais}

O presente artigo, apoiado na teoria sociocultural da mente (VYGOTSKY, 1978) e, mais especificamente, no conceito de lingualização (SWAIN, 2006), em contexto de instrução-focada-na-forma, teve por objetivo demonstrar que não só alunos de nível adiantado de IL2 e ILE podem se beneficiar do processo de lingualização mas também os de nível mais elementar. Teve ainda o objetivo de mostrar que a alegação de que a reflexão sobre uso de língua pode funcionar, isto é, trazer benefícios ao aprendiz, tanto se se lingualizar em língua materna (L1) como em língua estrangeira (LE). Essa possibilidade parece bastante útil em contexto brasileiro, uma vez que apenas lingualizar na língua-alvo no Brasil poderia excluir muitos aprendizes da oportunidade de crescimento linguístico por meio do referido processo.

Nos estudos aqui resumidos, ficou bastante claro que, ao lingualizar sobre uso da língua, os aprendizes fizeram da língua-alvo objeto de estudo e meio de aprendizagem. Ao refletir sobre o uso da língua, concomitantemente com a produção nessa mesma língua, os aprendizes foram capazes de construir, reconstruir e coconstruir significados e exprimir suas mensagens mediando, pela língua, seu próprio desenvolvimento linguístico e sua aprendizagem. Em alguns dos estudos relatados, os diálogos colaborativos, isto, é a interação negociada que levava à construção do conhecimento e à resolução de problemas não foi gravada, mas, mesmo assim, aconteceu e se pode observar, neste caso, por meio do produto e de questionários, o quanto os próprios aprendizes dizem ter se enriquecido com o procedimento.

De modo geral, o que se pode perceber com essa teorização sobre o papel da produção por meio da lingualização é que a consciência linguística parece realmente importante na aprendizagem de línguas, ganhando mesmo força no campo da ASL (SVALBERG, 2007). Além disso, a área do ensino da gramática, da instrução-focada-na-forma, pode ser muito enriquecida com a combinação das diferentes opçóes de ensino da forma; isto é, com a interligação da instrução baseada no insumo, com a instrução explícita, com a instrução baseada no feedback corretivo (ELLIS, 1998; VIDAL, 2007c), alicerçadas na instrução baseada na produção, sendo esta última a que parece merecer maior ênfase.

Acresce ainda que a pesquisa no campo da Linguística Aplicada / aprendizagem de L2, tanto no exterior quanto no Brasil, além de necessitar de uma ampla discussão dos princípios que podem oferecer respaldo teórico para as investigaçoes, parece precisar de trabalhos que repliquem estudos já realizados para se poder, com maior segurança, chegar a conclusóes mais efetivas do processo ensino-aprendizagem de línguas nos diferentes contextos socioculturais. 


\section{Referências}

BASTOS, F. B. de M. Teaching EFL to Young learners: MI theory and interaction. 2005. Monografia (Curso de Especialização em Linguística Aplicada: ensino / aprendizagem de inglês como língua estrangeira) - UFF, 2005.

BASSI, C. E.; DUTRA, D. P. A interação e o processo de negociação. Revista Brasileira de Linguística Aplicada, Belo Horizonte, v. 4, n. 1, p. 291-313, 2004.

DONATO, R. Aspects of collaboration in pedagogical discourse. Annual Review of Applied Linguistics. 24, p. 284-302, 1984.

DONATO, R. Sociocultural contributions to understanding the foreign and second language classroom. In: LANTOLF, James, P. (Ed.). Sociocultural theory and second language learning. Oxford: OUP, 2000.

DOUGHTY, C.; WILLIAMS, J. (Ed.). Focus on form in classroom second language acquisition. Cambridge: CUP, 1998.

ELLIS, R. Teaching and research: options in grammar teaching. TESOL Quarterly, v. 32, n. 1, p. 39-60, 1998.

ELLIS, R. Introduction: Investigating form-focused instruction. Language Learning S1: Supplement 1, p. 1-46, 2001.

FIGUEIREDO, J. C. de $S$. The use of reformulation as a means of corrective feedback in an EFL classroom. Monografia de conclusão do curso "A instruçãofocada-na-forma e o diálogo colaborativo" apresentada como requisito parcial para crédito da disciplina Ensino e aprendizagem de Língua Estrangeira à Prof. Rejane Teixeira Vidal, UFF, (Manuscrito), 2006.

HAWKINS, E. W. Modern languages in the curriculum. In: PERREN, G. (Ed.). The space between: English and Foreign languages at school. London: Philip, 1974. HAWKINS, E. W. Foreign language study and language awareness. Language Awareness, v. 8, n. 3 e 4, p. 24-142, 1999.

KOWAL, M.; SWAIN, M. From semantic to syntactic processing. How can we promote it in the immersion classroom? In: Keith Johnson, R. and Merrill Swain (Ed.). Immersion Education: international perspectives. Cambridge, CUP, 1997. KRASHEN, S. Principles and practice in second language acquisition. Oxford: Pergamon, 1982.

LANTOLF, J.; APPEL, G. (Ed.). Vygostskian approaches to second language research. Norwood, N. J: Ablex, 1994.

LANTOLF, J. P. (Ed.). Sociocultural theory and second language learning. Oxford, OUP, 2000.

LARSEN-FREEMAN, D. Chaos/complexity science and language acquisition. Applied Linguistics, Oxford: OUP, v. 18, n. 2, 1997. 
LEFFA, V. J. Transdisciplinaridade no ensino de línguas: a perspectiva das teorias da complexidade. Revista Brasileira de Linguística Aplicada, Belo Horizonte, v. 6, n. 1, p. 27-49, 2006.

LIMA, M. dos S.; PINTO, I. da C. A tarefa colaborativa como estímulo à aprendizagem de língua estrangeira. In: LIMA, Marília dos S.; GRAÇA, Rosa Maria de O. (Ed.). Ensino e Aprendizagem de Lingua Estrangeira: Relações de Pesquisa Brasil/Canadá. Porto Alegre: Armazém Digital, 2007. p. 87-99.

LONG, M. H.; PORTER, P. Group work, interlanguage talk and second language acquisition. TESOL Quarterly, 19, 1985. p. 207-228.

LONG, M. H. Focus on form: A design feature in language teaching methodology. In: GINSBERG, K. de Bot, R.; KRAMSCH, C. (Ed.). Foreign Language Research in cross-cultural perspective. Amsterdam: John Benjamins, 1991. p. 39-52.

LONG, M. H. 2007. Texts, tasks and the advanced learner. In: LONG, Michael H. Problems in SLA. New York: Lawrence Erlbaum, 2007.

LONG, M.; ROBINSON, P. Focus on form: theory, research, and practice. In: DOUGHTY, C.; WILLIAMS, J. (Ed.). Focus on form in classroom second language acquisition. Cambridge: CUP, 1998.

McLAUGHLIN, B.; ROSSAMAN, T.; McLEOD, B. Second language learning: An information processing perspective. Language Learning, 33, p. 135-158, 1983. MITCHELL, R.; MYLES, F. Second language learning theories. 2. ed. London: Hodder Arnold, 2004.

MOREIRA, M. A. O. "Discutindo e pensando a gente pode corrigir os erros". A instrução focada na forma através da produção escrita: uma experiência na escola pública. Monografia de conclusão do curso "A instrução-focada-na-forma e o diálogo colaborativo" apresentada como requisito parcial para crédito da disciplina Ensino e aprendizagem de Língua Estrangeira à Prof. Rejane Teixeira Vidal, UFF (Manuscrito), 2006.

NORRIS, J. M.; ORTEGA, L. Effectiveness of L2 instruction: A research synthesis and quantitative meta-analysis. Language Learning, v. 50, n. 3, p. 417-528, 2000. NUNAN, D. Designing tasks for the communicative classroom. Cambridge, CUP, 1989. PAIVA, V. L. M. O. Fractal model of language acquisition. In: BRUNO, F. C. (Ed.). Reflexão e prática em ensinolaprendizagem de língua estrangeira. São Paulo: Editora Clara Luz, 2005. p. 23-36.

QI, S. D.; LAPKIN, S. Exploring the role of noticing in a three-stage second language writing task. Journal of Second Language Writing, v. 10, p. 277-303, 2001.

SCHACHTER, J. A universal input condition. In: Rutherford, W. (Ed.). Universals and second language acquisition. Amsterdam: John Benjamins, 1984. 
SEBA, R. G. From collaborative writing to reading comprehension: a pilot study on form focus as a means to enhance reading comprehension in ESP classes. Monografia de conclusão do curso "A instrução-focada-na-forma e o diálogo colaborativo" apresentada como requisito parcial para crédito da disciplina Ensino e aprendizagem de Língua Estrangeira à Prof. Rejane Teixeira Vidal, UFF, (Manuscrito), 2006.

SMITH, F. Reading without nonsense. New York: Teacher's College Press, 1978. SPADA, N. Form-focussed instruction and second language acquisition: A review of classroom and laboratory research. Language Teaching, 30, 73-87, Cambridge, CUP, 1997.

SPADA, N.; LIGHTBOWN, P. M. Form-Focussed Instruction: Isolated or integrated? TESOL Quarterly, 2007. (no prelo)

SVALBERG, A. M-L. Language awareness. State-of-the-art-article. Language Teaching, Cambridge: CUP, v. 40, p. 287-308, 2007.

SWAIN, M. Communicative Competence: Some roles of Comprehensible Input and Comprehensible Output in its Development. In: GASS, S.; MADDEN, C. G. (Ed.). Input in Second Language Acquisition. Rowley, MA: Newbury House, 1985. SWAIN, M. Three functions of output in second language learning. In: Cook andG. B. Seidlhofer (Ed.). Principle and Practice in Applied Linguistics. Oxford, OUP, 1995.

SWAIN, M.; LAPKIN, S. Problems in output and the cognitive processes they generate: A step towards second language learning. Applied Linguistics, 16, 3 , p. 370-391, 1995.

SWAIN, M. The output hypothesis and beyond: Mediating acquisition through collaborative dialogue. In: JAMES, P. Lantolf (Ed.). Sociocultural theory and second language learning. Oxford: OUP, 2000.

SWAIN, M. Languaging, agency and collaboration in advanced second language learning. In: BYRNES, H. (Ed.). Advanced language learning: The contributions of Halliday and Vygotsky. London, UK: Continuum. 2006.

SWAIN, M.; LAPKIN, S. Talking it through: two French immersion learners' response to reformulation. International Journal of Education Research, v. 37, p. 285-304, 2002.

VIDAL, R. T. Interlanguaging stretching: the role of consciousness-raising communicative tasks and metatalk. 2003. Tese (Doutorado) - Instituto de Letras, UFF, Rio de Janeiro, 2003.

VIDAL, R. T. O diálogo colaborativo, individual ou em par, e o desenvolvimento da interlíngua em tarefas de metafala. Revista do ISAT, São Gonçalo, RJ: ICBEU, v. 3, p. 17-38, 2004. 
VIDAL, R. T. Form-focused tasks, collaboration via metatalk and interlanguage stretching. In: LIMA, Marília dos Santos; GRAÇA, Rosa Maria de Oliveira (Ed.). Intersecções pedagógicas no ensino de línguas estrangeiras: Brasil-Canadá. Porto Alegre: Armazém Digital, 2007a. p. 171-198.

VIDAL, R. T. EFL learners' self-evaluation of learning processes after metatalk tasks. Revista Brasileira de Linguistica Aplicada, Belo Horizonte, v. 7, n. 1, p. 117148, 2007b.

VIDAL, R. T. Ensino-aprendizagem do foco na forma: retorno ou recomeço? The Especialist, São Paulo: Educ, v. 28, n. 2, 2007c.

VYGOTSKY, L. S. Mind in society. Cambridge, Massachusetts: Harvard University Press, 1978.

WILLE de SOUZA, A. C. Basic level students and focus-on-form: a study in a public school. Monografia de conclusão do curso "A instrução-focada-na-forma e o diálogo colaborativo" apresentada como requisito parcial para crédito da disciplina Ensino e aprendizagem de Língua Estrangeira à Prof. Rejane Teixeira Vidal, UFF, (Manuscrito), 2006.

WILLIAMS, J. Learner generated attention to form. Language Learning, 49, 4, p. 583-625, 1999.

WILLIAMS, J. Focus on form: Research and its application. Revista Brasileira de Linguistica Aplicada, Belo Horizonte, v. 1, n. 1, p. 31-52, 2001.

Recebido em 30/10/08. Aprovado em 24/05/09. 